\title{
Building Bridges between healthcare professionals, patients and families: A coproduced and integrated approach to self-management support in stroke
}

\author{
Fiona Jones $^{\mathrm{a}, *}$, Heide Pöstges ${ }^{\mathrm{b}}$ and Lucinda Brimicombe ${ }^{\mathrm{b}}$ \\ ${ }^{a}$ Faculty of Health Social Care and Education, St Georges University of London and Kingston University, \\ London, UK \\ ${ }^{\mathrm{b}}$ Faculty of Health Social Care and Education, St Georges University of London and Kingston University/Bridges \\ Self-Management, London, UK
}

\begin{abstract}
.
BACKGROUND: Programmes providing self-management support for patients and families are gaining attention and have shown promising outcomes with regards to reducing long-term unmet needs post stroke. However, notions of what good selfmanagement support looks like can differ depending on professional opinion, individual preferences, skills and experiences of patients and their families as well as on how care and rehabilitation is organised in a particular healthcare setting. This resonates with the perspective of patient-centred care, according to which the meaning of good care is not universal, but rather jointly shaped between healthcare professionals and patients in everyday interactions. While self-management support is continuously co-produced in care and rehabilitation practices, most self-management programmes are typically provided as an 'add-on' to existing statutory care.

OBJECTIVE: This paper aims to deepen the understanding of how self-management support can be made an integral part of everyday care and rehabilitation using Bridges methodology.

METHODS: The authors provide a self-reflective account on 'Bridges' an integrated approach to self-management support, which is used by healthcare professionals within acute and community stroke rehabilitation across the UK, and in some parts of New Zealand and Australia.

RESULTS: Bridges is based on self-efficacy principles, but has a central aim of professionals sharing decision-making and expertise with patients and families in every healthcare interaction. Methodologically, the co-production of a Bridges support package with local healthcare professionals and patients is critical. The authors present the values articulated by the support package and how it engages professionals, patients and Bridges training facilitators in a continuous process of adjusting and re-adjusting situated self-management support practices.

CONCLUSIONS: Our reflections reveal the need to consider development and implementation of self-management support as one and the same on-going process, if we are to facilitate successful engagement and interest from healthcare professionals as well as their patients and families.
\end{abstract}

Keywords: Self-management, co-production, stroke, long-term conditions

\footnotetext{
*Address for correspondence: Fiona Jones, PhD, MSc, FCSP, Professor, Rehabilitation Research, Faculty of Health Social Care and Education, St. George's Hospital, University of London and
}

Kingston University, 2nd Floor Grosvenor Wing, Cranmer Terrace, London SW17 0RE, UK. Tel.: +44 0208725 2259; E-mail: f.jones@sgul.kingston.ac.uk. 


\section{Background}

Stroke is one of the most common causes of long term disability (Feigin et al., 2014). Annually there are 17 million incidences of stroke worldwide and in the UK 1.2 million people at any one time are living with the consequences of stroke (Stroke Association, 2016). Notwithstanding all the advances in primary prevention and acute care, stroke survivors' emotional, social and physical needs in the longer term are unquestionably high (McKevitt et al., 2011; Pollock, St George, Fenton, \& Firkins, 2012). Selfmanagement support relates to the help given to people with long-term conditions to manage their health on a day to day basis, and studies have shown an impact on confidence, skills and knowledge as well as psychosocial and physical health (de Silva, 2011; Parke et al., 2015). Mindful of potential hyperbole about the benefits of self-management programmes for individuals with long-term conditions, they could offer solutions to long term unmet need post stroke. But herein lays the paradox, those that potentially could have the most to gain such as those with complex conditions or low health literacy or poor social support systems can be amongst those excluded or not engaging with self-management programmes (Coulter \& Ellins, 2007; de Silva, 2011). Our own research has shown that individuals with cognitive and communication problems such as aphasia are not recruited into self-management studies at the same rate as other stroke survivors (Jones et al., 2016). Despite a third of stroke survivors experiencing aphasia, self-management programmes delivered in a structured way with a focus on written or spoken methods could be alienating environments (Stroke Association, 2015) and yet individuals with aphasia are more likely to have long term unmet needs and depression (Ayerbe, Ayis, Wolfe, \& Rudd, 2013). Indeed, there may be many and varied reasons why individuals do not engage in standardised selfmanagement support. Several authors have noted the inherent inequity of self-management programmes as favouring those with good health literacy and motivations to engage (Kendall, Catalano, Posner, Buys, \& Charker, 2007; Taylor \& Bury, 2007). In fact, non-engagement could be entirely understandable in someone living with a complex long term condition such as stroke and facing challenging personal, social or cognitive circumstances (Hinder \& Greenhalgh, 2012). Understanding how we as professionals can create an environment, which is inclusive, open and collaborative, is critical to enable self-management skills to flourish post stroke.

We are now at a pivotal point in our own understanding of the challenges and complexities of delivering self-management support post stroke using an individualised provider-based approach to supported self-management called 'Bridges'. In this paper we will draw on different theoretical perspectives and evidence to illustrate our direction and influences, as well as reflecting on our own evolving practice in self-management. The training of more than 120 multi-professional stroke rehabilitation teams across the UK has taught us that we all need to work hard to develop skills, which have equality and partnership at their core. We have also gained an understanding through our research and that of others that efficacy in a trial setting is not enough to determine whether a self-management intervention will be successful or not (Kennedy et al., 2013; McKenna, Jones, Glenfield, \& Lennon, 2013; Jones et al., 2016). We have more recently drawn on implementation science to understand how stroke rehabilitation teams can successfully normalise self-management support into their everyday practice and sustain this way of working (Damschroder et al., 2009; Eccles et al., 2009). We end this paper by using exemplars to illustrate how Bridges has been used in stroke rehabilitation not just post hospital but in the most biomedical of environments, an acute stroke unit.

\subsection{The hazard of fostering dependency on professional expertise early on}

Clearly the first few days and weeks post stroke will start with a biomedical focus on recovery of impairment and condition management by stroke experts. But it is at this stage that rehabilitation delivered in an acute stroke care setting can unwittingly preference the competencies and techniques of therapists over and above the contributions and skills of patients and families (Levack, Dean, Siegert, \& McPherson, 2011; Taylor, 2014). In the UK, stroke rehabilitation is largely delivered according to pre-determined national guidelines which specify physiotherapy, occupational therapy and speech and language therapy at certain levels of intensity (Intercollegiate Stroke working Party, 2012; National Institute of Health and Clinical Excellence, 2013). This period of intense support and care delivered in hospital stroke units can be hard for individuals to equate with an expectation that by time of discharge, 
they will be able to self-manage (Wiles, Ashburn, Payne, \& Murphy, 2004). The whole notion of person centred care is worth considering here and often overlaps with definitions of self-management support (Ahmad, Ellins, Krelle, \& Lawrie, 2014; Makela, Gawned, \& Jones, 2014). Both include key principles such as enabling individuals to develop their own strengths and abilities to live a fulfilling life (Ahmad et al., 2014). Retaining a focus on person centred approaches and self-management support can be challenging in an acute medical environment (Makela, Gawned, \& Jones, 2014). Yet real partnership working which equally values the skills and expertise of individuals with their acute medical condition as much as those of the professional can create tangible self-management opportunities. Nonetheless, therapeutic relationships and experiences of rehabilitation in hospital and specialist rehabilitation settings may prove all too powerful in fostering reliance on clinical expertise and inadvertently undervaluing the ideas and solutions which could exist within each individual (Coulter, Roberts, \& Dixon, 2013). Indeed, studies show goal setting in stroke rehabilitation can be professionally determined in many instances and rehabilitation can leave little opportunity to explore and shape self-management relevant to an individual's needs and preferences (Brown et al., 2013; Levack et al., 2011; Norris \& Kilbride, 2013). Additionally, an environment in which professionals protect patients from making what they perceive as irrational and irresponsible choices or prioritise 'realistic' goals runs the risk of creating an imbalanced relationship from the start, rather than good care which is jointly shaped by reciprocal and open interactions. The field of selfmanagement research whilst acknowledging the role of long-term condition education now consistently highlights the value of tailoring support to the needs of individuals (Ahmad et al., 2014; de Silva, 2011). Self-management support is clearly not a 'one-size fits all' and our understandings of the importance of context and mechanisms, which may work for individuals post stroke, are now emerging.

\subsection{History of Bridges}

Bridges is a self-management approach that has evolved from a 10-year programme of research and focuses strongly on the quality of interactions required by health care professionals in order to support knowledge, confidence and skills in patients living with long-term conditions. The Bridges selfmanagement programme began in stroke but has now extended to brain injury and other complex neurological conditions and in acute and community healthcare settings (Jones, Mandy, \& Partridge, 2009; Makela, 2015). Social cognition theory has underpinned our work and self-efficacy was a critical first construct within Bridges (Bandura, 1997). The use of mastery experiences woven into every rehabilitation session to help patients understand their own contribution to progress and self-management was an important 'active ingredient' of the approach. Patients have their own Bridges workbook to record what goals matter to them, and therapeutic interactions with professionals that focus on supporting confidence and relevant skills and knowledge required by patients to self-manage. Social cognition theory informed the content of the Bridges workbooks by incorporating the principles of modelling and vicarious learning through sharing experiences, challenges and successes of other stroke survivors. Each workbook contains vignettes of different people living and managing their condition, which can act as an inspiration or source of ideas. There is also space within the book to record individual thoughts and plans, and to reflect on progress, ideas and actions, which have helped progress. Although the Bridges workbook provides a structure around which self-management can be shaped, it does not negate the need for professionals to use language and techniques, which facilitate self-management in a non-directive way. In fact the workbook can be perceived as a limiting factor for engagement in self-management and has led to gatekeeping by rehabilitation professionals when considering the potential challenges faced by people with aphasia and other cognitive impairments (Jones, 2016). To focus on a tool such as the workbook to support self-management is clearly not enough, a view strongly endorsed by others (Ahmad et al., 2014; de Silva, 2011).

Research to develop and test the Bridges stroke self-management programme has shown proof of concept, efficacy, acceptability and feasibility as an approach integrated into rehabilitation (Jones et al., 2009, 2012, 2016; McKenna et al., 2013). But we are now mindful that evidence in a trial setting does not help us understand how rehabilitation teams and professionals integrate and sustain self-management support which preferences needs, goals and skills of individuals. Specifically, we have been keen to understand how self-management is perceived and 
enacted by professionals and how teams can create a shared understanding of self-management through their organisational processes. We have shown that multi-professional teams can change their practice, gain knowledge and experience of supporting individuals to self-manage and use less didactic and directive approaches in rehabilitation (Jones \& Bailey, 2012; Jones et al., 2012). This approach has been well received by stroke survivors, who perceive that Bridges enables them to manage their progress, set goals of a personal nature, and gain greater understanding of recovery post stroke (McKenna et al., 2013).

We now need to consider other relevant theories and concepts of self-management which can help advance our approach so that it can have the rigidity to be sustained overtime, but the flexibility to evolve and tailor to individual needs.

\subsection{From specific behaviour change to situated everyday practices}

Our emerging understandings of self-management through our work to develop Bridges has now led us to widen our gaze to other theories and concepts beyond that of personal agency and learning theories such as social cognition theory. An increasing focus of research within critical health psychology and the social sciences reveals that patients' health behaviour is never only cognitively motivated, but rather interlinked with wider social practices (Harrocks \& Johnson, 2014). In practice we have found professionals attributing patients' difficulties with self-management to cognitive or mood difficulties (Jones Livingstone \& Hawkes, 2012). But engagement in self-management can be influenced both positively and negatively by numerous other social and personal interactions (Hinder \& Greenhalgh, 2012; Rogers et al., 2014). The Bridges approach has attempted to move beyond the idea of patient engagement whereby individuals are expected to take on responsibility for making choices related to their condition towards a practice-based approach to selfmanagement support that takes the social context in which the individual is managing into account. This requires professionals to critically reflect on their own assumptions about how an individual should self-manage and create a space whereby the way to self-manage is jointly determined.

In essence we now believe that a strong focus on clinical symptom management or adherence to professional advice could potentially hinder the moti- vation of patients and their families to play a more active role in the rehabilitation process, since it ignores their social and material needs. Patients can be more motivated to engage in activities that help to maintain or re-shape a coherent identity and everyday life (Ellis-Hill, Payne, \& Ward, 2008; Ong et al., 2014). Professionals, however, can dismiss such activities as irrelevant or even problematic, especially when they are not consistent with or contradicting professional agendas (Ong et al., 2014).

It is also important to consider that the word 'selfmanagement' may itself be a hindrance and can be construed as being 'left to get on with it' (Satink et al., 2013). Approaches to self-management support require equal attention to the guidance and professional expertise required by patients and their families especially in earlier phases post stroke (Sadler, Wolfe, \& McKevitt, 2014). However, it is the concept of compliance models which can be at odds with nurturing and encouraging self-management. Ong et al. (2014) supports moving beyond promoting compliance with clinical advice towards a broader concept of self-management which comprises a continued search for meaning and legitimacy of the chronic condition and the negotiation of a new personal and social equilibrium. From this extended viewpoint, these very same activities that professionals may dismiss as hindering the rehabilitation process can become more relevant. We can even begin to understand them as a resource to engage someone who finds it difficult or is unwilling to make self-determined choices, since these everyday activities are not solely based on rational-decision making and develop out of situated actions and interactions (Cohn, 2014). Exploring with patients what they and their families already do and why it is important to them can hence offer a starting point for selfmanagement support. This can be followed by jointly agreed activities that include exploring and testing out new options as well as fine-tuning existing activities until a satisfying compromise is reached (Mol, 2006). Here, self-management involves professionals building supporting relationships with patients to work out practical skills that are tailored to individual needs and local situations.

In order to shape and produce self-management solutions professionals will also require a high degree of sensitivity to local needs and social circumstances in order to help patients to work out which health practices are most beneficial to them and their families (Horrocks \& Johnson, 2014). Professionals may have to relinquish a degree of power in their inter- 
actions with patients, and critical changes have to be supported by a shared understanding of working to support self-management at organisational level (Norris \& Kilbride, 2013; Ong et al., 2014). Our own work now focuses heavily on understanding the organisational processes, which may hinder promoting self-management (Jones et al., 2012). We explore, for instance, alternatives to standardised goal setting methods in order to provide more opportunity for individuals to prioritise personal and socially driven goals. We also encourage teams not to 'gate keep' and only consider self-management when an individual 'appears' motivated. As previously suggested, seemingly 'unmotivated patients' may have the most to gain by being supported to self-manage, a view shared by other commentators (Coulter \& Ellins, 2007). In addition, success occurs not only if a patient is motivated and engaged, but when a team or organisation has critically reflected on how they need to change their language and processes to emphasise greater partnership working. We believe that those selfmanagement interventions, which are more or less exclusively based on individual behaviour change, can ignore important structural issues as an explanation for behaviour and engagement (Ong et al., 2014).

\subsection{Time for questions: how is self-management constructed and enacted?}

A large synthesis of evidence from selfmanagement programmes ranging from simple educational provision to more structured behaviour change interventions found that self-efficacy was the most common underpinning construct and more likely to be used in successful programmes. There was, nonetheless, wide variation in how selfmanagement support was enacted by healthcare professionals (de Silva, 2011). While research has continued at a high pace and self-management still features in health policy as an answer to long term condition management (Coulter et al., 2013; NHS England, 2014), a recent large scale self-management study in primary care showed we are still a long way from finding the formula for successful implementation (Kennedy et al., 2013).

There is now a critical question about the very nature of what self-management is and should be. Here, we are not only dealing with concerns about the feasibility and effectiveness of a specific selfmanagement intervention, but a deeper ontological question. Finding an answer requires an investiga- tion into the impact of such interventions on everyday life in order to render visible what works well and which aspects need improving (Mol, 2006). This widens the focus of our analysis from merely defining Bridges self-management (epistemology) to investigating how it is experienced and enacted in everyday practices (ontology). By critically reflecting on how 'Bridges self-management' has evolved since its inception, we demonstrate how this approach has enhanced over time to reinforce values, which prioritise partnership between patients, families and professionals.

The concept of boundary objects may also be helpful as a conceptualisation of Bridges. Boundary objects were originally described as 'objects which are both plastic enough to adapt to local needs and constraints of the several parties employing them, yet robust enough to maintain a common identity across sites' (Star \& Greisemer, 1989). Boundary objects like the concept of self-management have different meanings in different situations and contexts and the key to implementation is to develop and maintain coherence of the boundary object across different situations. Our own challenge has been to communicate evidence from our research and that of others which can convince healthcare professionals of the potential of self-management support whether using the Bridges book or not. Alongside that there is the need for healthcare professionals to communicate these messages to encourage stroke survivors that there are personal gains to be made from engaging with self-management strategies and ideas. It has been necessary for us to develop a shared language of self-management, which can represent and attract the interest of different parties. This has been possible through the cumulative input of many hundreds of healthcare professionals enacting and integrating self-management support and feeding back to us about their successes and challenges (Jones, Livingstone, \& Hawkes, 2012). By arriving at a shared meaning and learning from each other's perspectives we aim to move more towards a 'community of practice' which has the potential to both understand and facilitate adoption of Bridges as an innovation (Fox, 2011).

\subsection{Telling the whole story, beyond efficacy testing}

A recent cluster randomised controlled trial which tested the integration of Bridges into the everyday practices of community stroke teams enabled critical 
steps towards understanding and defining the hallmarks and fidelity of the approach (Jones et al., 2016). Healthcare professionals from the intervention teams worked alongside the research team to explicitly define the strategies and language that exemplified seven Bridges principles. These included knowledge, goal setting, self-discovery, problem solving, accessing resources, reflection, and taking action. This exercise helped to both define and make sense of Bridges in the community stroke setting which in turn helped identify the behaviours necessary to implement and sustain the approach. Encouraging professionals and teams to define and conceptualise self-management support relevant to the needs of their caseload and service has now become an integral part of the training we deliver in health and social care.

In addition Normalisation Process Theory (NPT) now forms a critical framework for us to understand how to implement a complex intervention such as Bridges self-management support into everyday clinical practice, so that it becomes 'normalised' (May \& Finch, 2009; May et al., 2009; Murray et al., 2010). Within the framework, implementation is defined as a complex and emergent social process, in which healthcare professionals collectively produce and embed new practices into their everyday work (May $\&$ Finch, 2009). NPT operationalises implementation according to four concepts: coherence e.g. how is Bridges different to usual practice?; cognitive participation e.g. will healthcare professionals be prepared to invest time and energy to implement Bridges?; collective action e.g. how will healthcare professionals make Bridges part of their daily practice?; and reflexive monitoring e.g. how will healthcare professionals know the impact of Bridges on outcomes? (May \& Finch, 2009). Through NPT the importance of considered engagement of healthcare professionals during the cycle of a research project or Bridges training, has formed another way of co-producing self-management with those that will enact the support within their practice.

The value of co-production has been pivotal through our work both to develop the Bridges workbook and shape our training programmes for healthcare professionals. Co-production is a term commonly used in health policy and broadly describes any collaborative relationship. In healthcare, the co-production of health services means service users and providers working together, to plan and deliver services and share decision-making (Realpe \& Wallace, 2010). This requires a shift in the balance of power whereby patients are seen as equals and experts. We have sought to reflect the values of co-production in our stroke workbook, so that it reflects the needs of stroke survivors as they define them. We also endeavour to foster collaborative relationships with healthcare professionals through our training and project work, by acknowledging their expertise and working with them to define and deliver best practice in self-management support in their particular context. One example of this is when we introduce professionals to self-management principles and support them to develop their own catch phrases to use in everyday practice. In between the two-stage training (usually 12 weeks) professionals test out ways of integrating self-management language and strategies and use self-reflection forms to share their experiences with us and their colleagues.

In this sense, we seek to model as trainers and facilitators the collaborative behaviours required by healthcare professionals to provide good selfmanagement support to their patients. This requires all of us to relinquish power and work in a way that has equality and partnership at its core (Norris \& Kilbride, 2014). In other words, we endeavour to practice what we preach.

\section{How is self-management support actually integrated in practice?}

Emerging research has shown that healthcare professionals can have very different understandings of self-management support (Mudge, Kayes, \& McPherson, 2016; van Hooft, Dwarswaard, Jedeloo, Bal, \& van Staa, 2015; Young et al., 2015). This supports our view and that of others that it is imperative to train whole teams, preferably using methods to facilitate interprofessional discussion and exchange (Reeves, Perrier, Goldman, Freeth, \& Zwarenstein, 2013). A recent synthesis of current ideas and evidence relating to self-management promotes the need to train the whole healthcare team together in order to deconstruct assumptions, build a shared understanding of self-management support and agree an implementation plan (Ahmad et al., 2014). Bridges training, developed through our experiences and informed by research, has sought to dispel the myths about self-management and common assumptions such as 1) self-management support is an 'add on' to usual clinical tasks; 2) it is something that is introduced before discharge from services; 3 ) or that it is difficult when stroke patients have severe physical, cognitive or communication impairments 
(Legare \& Thompson-Luduc, 2014). As already mentioned, our two-stage training incorporates time for healthcare professionals to reflect during and after practical implementation within rehabilitation. This recognises that teams benefit from discussion about the barriers and successes they have experienced in an interprofessional learning environment and support to work together to overcome any professional and organisational challenges (Reeves et al., 2008). In reality after practitioners implement the Bridges approach it is common for us to receive mixed feedback of practice successes and failures, usually outweighed by the latter. Skilled facilitation is required to create a supportive environment where everyone's contribution is valued and there are no right and wrong answers, within which the team can explore their mixed experiences. In doing so we strive to both create and model the team environment needed for this approach to flourish.

Anecdotally we have reflected on the notion that teams who have successfully integrated Bridges into their working practices have a fairly flat hierarchical structure, which seems to create a more open and supportive environment in which it becomes possible to explore different ways of working, and even blur professional boundaries. For example, a community stroke team in north England implemented Bridges through their support staff. They developed a specific 'Bridges appointment' at which the stroke workbook was introduced to facilitate a conversation about the stroke survivor as a person and what was meaningful to them. The support worker helped the stroke survivor to set goals and communicated those goals to the rest of the rehabilitation team, who constructed their treatment plans around the patient-defined goals.

Whilst we do not endorse this model of working per se, it illustrates our observation that stroke teams are more likely to successfully integrate Bridges when they liberate aspects of team processes and organisation. Another example comes from an acute stroke unit in London, U.K; after Bridges training, nursing staff and occupational therapists decided to work together to promote a ward ethos of helping patients to help themselves. The occupational therapists supported their nursing colleagues to change the washing and dressing routines, to enable stroke survivors to do more. Critically the occupational therapists listened to the nurses' concerns about this different way of working, such as it taking more time. They audited washing and dressing practices pre- and post-practice changes, which concluded amongst other things, that the changes didn't take up more of the nurses' time
(Gawned et al., 2014; Makela, Gawned, \& Jones, 2014).

It is a common perception that self-management support can take more time than usual practice (Legare \& Thompson-Luduc, 2014). However, our stance is that investing the time to listen to stroke survivors, to discover what is important and meaningful to them, could save time in the long-term. One community stroke team in our recent cluster-controlled trial (Jones et al., 2016) achieved comparable outcomes to the other intervention site, but with $50 \%$ less resources (face-to-face time). Anecdotally we receive feedback from Bridges-trained teams who have created a shared self-management ethos, that patients' episodes of care are shorter, with a reduction in onward referrals to other services. Whilst health and social care utilisation is one way to evaluate the impact of self-management support we encourage teams to evaluate the impact in other ways, in particular to produce questions they can add to existing team evaluation tools which reflect the self-management outcomes appropriate for their service. For example, an acute stroke service might ask the question at discharge 'how confident do you feel to manage things for yourself when you get home?' and a community stroke team might ask 'how confident do you feel to continue under your own steam?'

We recognise that services and teams evolve over time and so we support teams to plan for the sustainability of Bridges in practice. The community stroke team in north England had to re-think their implementation of Bridges when service changes meant that they no longer had time to do their selfdefined 'Bridges interview' with every stroke patient. Through refresher training we supported the team to work out ways to implement Bridges so it wasn't seen as an 'add on' but rather part of the way they work. This time around we focussed on the impact of their communication with stroke patients and families, and how all team members could use the stroke workbook as a tool to support self-management.

In the long-term, teams benefit from identifying 'Bridges champions' who are key change agents who can motivate the rest of the team to keep up changes in practice (Newbronner, Chamberlain, Borthwick, Baxter, \& Sanderson, 2013). Bridges champions can be healthcare professionals of any role or profession, who believe in the principles and act as role models to new and existing staff. Importantly, everyone in a rehabilitation team needs to feel supported by their managers and leaders, in order to work in new and innovative ways. 


\section{Conclusion}

Overall our reflections have revealed the need to consider development and implementation of self-management support as one and the same ongoing process if we are to facilitate successful engagement and interest from healthcare professionals as well as their patients and families. We have presented our experiences of a self-management innovation for stroke that goes beyond conventional self-management approaches based on behaviour change methods and reveals self-management support as a multiple and open-ended process.

Stroke teams defined in implementation terms as 'adopters' of Bridges have had to modify their own expectations and assumptions in order to consistently integrate self-management into rehabilitation as well as sustain over time. These teams such as the community stroke team mentioned have been prepared to change their processes in order to maintain a focus on what they feel is closer to a collaborative, person centred approach to self-management.

Our experiences support the need for further research to fully understand the context where selfmanagement support is delivered and received as well as the range of mechanisms through which support can be enacted. Perhaps more important is to advance our understanding of self-management outcomes which matter most to each stakeholder (patient, healthcare professional) as we suspect that there could be inherent differences between these parties when considering the impact of programmes. What constitutes success or failure in a self-management trial if there is no impact on a clinical outcome, but patients are more knowledgeable and confident as a result? A recent review in this area has revealed a range of different self-management outcomes are considered important by different stakeholders which include knowledge, skills and other biopsychosocial markers through to positive social networks (Boger et al., 2015).

Self-management as a concept has promised a great deal in tackling the increasing numbers of people living with conditions such as stroke. But surprisingly given the growing numbers of programmes and research published on the topic it is still a relatively under-theorised concept. Considering the complexity of both stroke and self-management and viewing Bridges as a Boundary object has helped us identify with the beliefs and values of our target groups such as rehabilitation professionals, and in turn the stroke survivors they are supporting. Our aim is to further develop into a community of practice to advance our understanding and build an evidence base to evaluate the impact of our programmes specifically with those individuals they are proposed to serve. We are now taking this learning forward to further test the use of Bridges in different settings and with different conditions including brain injury and progressive neurological conditions, and this will require a range of research methodologies. Bridges is now less about one condition, stroke, but the needs of individuals, the skills and roles of healthcare professionals and the organisational context in which self-management support is delivered. In other words, the whole system. We now need to illuminate what self-management support looks and sounds like so that it is neither alienating to patients nor burdensome to healthcare professionals. We still have a long way to go.

\section{Acknowledgments}

We acknowledge the input from our Bridges stakeholder reference and expert advisory groups and support from all the individual healthcare professionals and stroke rehabilitation teams that have contributed their feedback and ideas in the last 10 years.

\section{Conflict of interest}

FJ is the founder and director of the social enterprise Bridges Self-Management. HP and LB are both employed by Bridges Self-Management.

\section{References}

Ahmad, N., Ellins, J., Krelle, H., \& Lawrie, M. (2014). Person-centred care: From ideas to action. The Health Foundation: London. Retrieved from http://www.health. org.uk/publication/person-centred-care-ideas-action

Ayerbe, L., Ayis, S., Wolfe, C. D. A., \& Rudd, A. G. (2013). Natural history, predictors and outcomes of depression after stroke: Systematic review and meta-analysis. British Journal of Psychiatry, 202, 14-21.

Bandura, A. (1977). Self-efficacy: Towards a unifying theory of behavioural change. Psychology Review, 84(2), 191-215.

Boger, E., Ellis, J., Latter, S., Foster, C., Kennedy, A., Jones, F., Fenerty, V., Kellar, I., \& Demain, S. (2015). Self-management and self-management support outcomes: A systematic review and mixed research synthesis of stakeholder views. PLOS ONE, 10(7), e0130990. ISSN (online) 1932-6203

Brown, M., Levack, W., McPherson, K., Dean, S. G., Reed, K., Weatherall, M., \& Taylor, W. J. (2013). Survival, momentum, and things that make me "me": Patients' perceptions of 
goal setting after stroke. Disability and Rehabilitation, 36(12), 1020-1026.

Cohn, S. (2014). From health behaviours to health practices: An introduction. Sociology of Health and Illness, 36(2), 157-162.

Coulter, A., \& Collins, A. (2011). Making shared decision making a reality: No decision about me, without me. The Kings Fund: London. Retrieved from http://www.kingsfund. org.uk/publications/making-shared-decision-making-reality

Coulter, A., \& Ellins, J. (2007). Effectiveness of strategies for informing, educating, and involving patients. BMJ, 335, 24-27.

Coulter, A., Roberts, S., \& Dixon, A. (2013). Delivering better services for people with long-term conditions. Building the house of care. The Kings Fund: London. Retrieved from http:// www.kingsfund.org.uk/sites/files/kf/field/field_publication file/delivering-better-services-for-people-with-long-termconditions.pdf

Damschroder, L. J., Aron, D. C., Keith, R. E., Kirsh, S. R., Alexander, J. A., \& Lowery, J. C. (2009). Fostering implementation of health services research findings into practice: A consolidated framework for advancing implementation science. Implementation Science, 4, 50. http://dx.doi. org/doi:10.1186/1748-5908-4-50

de Silva, D. (2011). Evidence: Helping people help themselves. A review of the evidence considering whether it is worthwhile to support self-management. London: The Health Foundation. Retrieved from http://www.health. org.uk/publication/evidence-helping-people-help-themselves

Eccles, M. P., Armstrong, D., Baker, R., Cleary, K., Davies, H., Davies, S., Glasziou, P., Ilot, I., Kinmonth, A., Leng, G., Logan, S., Marteau, T., Michie, S., Rogers, H., Rycroft-Malone, J., \& Eccles, B. S. (2009). An implementation research agenda. Implementation Science, 4, 18. http://dx.doi.org/10.1186/1748-5908-4-18

Ellis-Hill, C. S. L., Payne, S., \& Ward, C. (2008). Using stroke to explore the Life Thread Model: An alternative approach to understanding rehabilitation following an acquired disability. Disability and Rehabilitation, 30(2), 150-159.

Feigin, V. L., Forouzanfar, M. H., Krishnamurthi, R., Mensah, G. A., Connor, M., Bennett, D. A., Moran, A. E., Sacco, R. L., Anderson, L. M., Truelsen, T., O'Donnell, M., Venketasubramanian, N., Barker-Collo, S., Lawes, C. M. M., Wang, W., Shinohara, Y.,Witt, E., Ezzati, M., Naghavi, M., \& Murray, C. (2014). Global and regional burden of stroke during 1990-2010: Findings from the Global Burden of Disease Study 2010. Lancet, 383, 245-255.

Fox, N. J., (2011) Boundary objects, social meanings and the success of new technologies. Sociology, 45(1) 70-85

Gawned, S., Wulf, K., Foster, D., Styles, J., Jones, F., \& Makela, P. (2014). 'Early Bridges': Adapting the Bridges self-management programme for the acute stroke setting. International Journal of Stroke, 9(4), 19.

Hinder, S., \& Greenhalgh, T. (2012). "This does my head in". Ethnographic study of self-management by people with diabetes. BMC Health Services Research, 12, 83. http://dx.doi.org/10.1186/1472-6963-12-83

Horrocks, C., \& Johnson, S. (2014). A socially situated approach to inform ways to improve health and wellbeing. Sociology of Health and Illness, 36(2), 175-186.

Intercollegiate Stroke Working Party (2012). National Clinical Guidelines for Stroke, 4th edition. Royal College of Physicians: London. Retrieved from https://www.rcplondon. ac.uk/guidelines-policy/stroke-guidelines
Jones, F., \& Bailey, N. (2013). How can we train stroke healthcare professionals about self-management? Description and evaluation of a pathway wide training programme. European Journal of Person Centered Healthcare, 1(1), 246-254.

Jones, F. (2013). Self-management: Is it time for a new direction in rehabilitation and post stroke care? Panminerva Medica, 55(1), 79-86.

Jones, F., \& Riazi, A. (2010). Systematic review of self-efficacy and stroke. Disability and Rehabilitation, 33(10), 797-810.

Jones, F., Benson, L., Jones, C., Waters, C., Hammond, J., \& Bailey, N. (2012). Evaluation of a shared approach to interprofessional learning about stroke self-management. Journal of Interprofessional Care, 26(6), 514-516.

Jones, F., Gage, H., Drummond, A., Bhalla, A., Grant, R., Lennon, S., McKevitt, C., Riazi, A., \& Liston, M. (2016). Feasibility study of an integrated stroke self-management programme: A cluster-randomised controlled trial. BMJ Open, 6, http://dx.doi.org/10.1136/bmjopen-2015-008900

Jones, F., Livingstone, E., \& Hawkes, L. (2012). Getting the balance between encouragement and taking over: Reflections on using a new stroke self-management programme. Physiotherapy Research International, 18(2), 91-99.

Jones, F., Mandy, A., \& Partridge, C. (2009). Changing selfefficacy in individuals following first stroke: Preliminary study of a novel self-management intervention. Clinical Rehabilitation, 23(6), 522-533.

Jones, F., Riazi, A., \& Norris, M. (2012). Self-management after stroke: Time for some more questions? Disability and Rehabilitation, 35(3), 257-264.

Kendall, E., Catalano, T., Posner, N., Buys, N., \& Charker, J. (2007). Recovery following stroke: The role of selfmanagement education. Social Science and Medicine, 64, 735-746.

Kennedy, A., Bower, P., Reeves, D., Blakenham, T., Bowen, R., Chew-Graham, C., Eden, M., Fullwood, C., Gaffney, H., Gardner, C., Lee, V., Morris, R., Protheroe, J., Richardson, G., Sanders, C., Swallow, A., Thompson, D., \& Rogers, A. (2013). Implementation of self-management support for long term conditions in routine primary care settings: Cluster randomised controlled trial. BMJ, 346, http://dx.doi.org/doi:10.1136/bmj.f2882

Kennedy, A., Chew-Graham, C., Blakeman, T., Bowen, A., Gardner, C., Protheroe, J., Rogers, A., \& Gask, L. (2010). Delivering the WISE (Whole Systems Informing Self-Management Engagement) training package in primary care: Learning from formative evaluation. Implementation Science, 5, 7. http://dx.doi.org/10.1186/1748-5908-5-7

Legare, P., \& Thompson-Luduc, P. (2014). Twelve myths about shared decision making. Patient Education and Counselling, 96, 281-286.

Levack, W., Dean, S., Siegert, R., \& McPherson, K. (2011). Navigating patient-centered goal setting in inpatient stroke rehabilitation: How clinicians control the process to meet perceived professional responsibilities. Patient Education and Counselling, 85, 206-213.

Makela, P. (2015). Shine 2014 final report. Early integration of the Bridges self-management support package into usual care following traumatic brain injury: A feasibility study. Retrieved from http://www.health.org.uk/sites/default/files/ Kings_Bridges_Shine\%202014\%20final\%20report_website _ version.pdf 
Makela, P., Gawned, S., \& Jones, F. (2014). Starting early: Integration of self-management support into an acute stroke service. BMJ Quality Improvement Reports, 3. http://dx.doi.org/doi:10.1136/bmjquality.u202037.w1759

May, C., \& Finch, T. (2009). Implementing, embedding and integrating practices: An outline of Normalization Process Theory. Sociology, 43(3), 535-554.

May, C. R., Mair, F., Finch, T., MacFarlane, A., Dowrick, C., Treweek, S., Rapley, T., Ballini, L., Ong, B. N., Rogers, A., Murray, E., Elwyn, G., Legare, F., Gunn, J., \& Montori, V. M. (2009). Development of a theory of implementation and integration: Normalization Process Theory. Implementation Science, 4, 29. http://dx.doi.org/ 10.1186/1748-5908-4-29

McKenna, S., Jones, F., Glenfield, P., \& Lennon, S. (2013). Bridges self-management program for people with stroke in the community: A feasibility randomized controlled trial. International Journal of Stroke, 10(5), 697-704.

McKenna, S., Martin, S., Jones, F., Gracey, F., \& Lennon, S. (2015). The Bridges stroke self-management program for stroke survivors in the community: Stroke, carer and health professional participants' perspectives. Physical Medicine and Rehabilitation International, 2(1), 1030-1036.

McKevitt, C., Fudge, N., Redfern, J., Sheldenkar, A., Crichton, S., Rudd, A. R., Forster, A., Young, J., Nazareth, I., Silver, L. E. Rothwell, P. M., \& Wolfe, C. D. (2011). Self-reported long-term needs after stroke. Stroke, 42, 1398-1403.

Mol, A. M. (2006). Proving or improving: On health care research as a form of self-reflection. Qualitative Health Research, 16, 405-415.

Mudge, S., Kayes, N., \& McPherson, K. (2016). Who is in control? Clinicians' view on their role in self-management approaches: A qualitative metasynthesis. BMJ Open, 5. http://dx.doi.org/ 10.1136/bmjopen-2014-007413

Murray, E., Treweek, S., Pope, C., MacFarlane, A., Ballini, L., Dowrick, C., Finch, T., Kennedy, A., Mair, F., O’Donnell, C., Ong, B. N., Rapley, T., Rogers, A., \& May, C. (2010). Normalisation Process Theory: A framework for developing, evaluating and implementing complex interventions. BMC Medicine, 8 , 63. http://dx.doi.org/10.1186/1741-7015-8-63

National Institute for Health and Care Excellence (2013) Stroke Rehabilitation in adults (CG:162). Retrieved from http://guidance.nice.org.uk/CG162

Newbronner, L., Chamberlain, R., Borthwick, R., Baxter, M., \& Sanderson, D. (2013). Sustaining and spreading selfmanagement support: Lessons from co-creating health phase 2. The Health Foundation: London. Retrieved from http://www. health.org.uk/publication/sustaining-and-spreading-selfmanagement-support

NHS England (2014). Five-year forward view. NHS England: Redditch. Retrieved from https://www.england.nhs.uk/ ourwork/futurenhs/

Norris, M., \& Kilbride, C. (2014). From dictatorship to a reluctant democracy: Stroke therapists talking about self-management. Disability and Rehabilitation, 36(1), 32-38.

Ong, B. N., Rogers, A., Kennedy, A., Bower, P., Sanders, T., Morden, A., Cheraghi-Sohi, S., Richardson, J. C., \& Stevenson, F. (2014). Behaviour change and social blinkers? The role of sociology in trials of self-management behaviour in chronic conditions. Sociology of Health \& Illness, 36(2), 226-238.

Parke, H. L., Epiphaniou, E., Pearce, G., Taylor, S. J. C., Sheikh, A., Griffiths, C. J., Greenhalgh, T., \& Pinnock, H. (2015). Self-management support interventions for stroke survivors: A systematic meta-review. PLoS ONE, 10(7). http://dx.doi.org/10.1371/journal.pone.0131448

Pollock, A., St George, B., Fenton, M., \& Firkins, L. (2012). Top ten research priorities relating to life after stroke. The Lancet, 11, 209.

Realpe, A., \& Wallace, L. M. (2010). What is co-production? The Health Foundation: London. Retrieved from http:// personcentredcare.health.org.uk/sites/default/files/resources/ what_is_co-production.pdf

Reeves, S., Perrier, L., Goldman, J., Freeth, D., \& Zwarenstein, M. (2013). Interprofessional education: Effects on professional practice and healthcare outcomes (update). Cochrane Database of Systematic Reviews, 2013(3), 1-49. doi:10.1002/14651858.CD002213.pub3.

Reeves, S., Zwarenstein, M., Goldman, J., Barr, H., Freeth, D., Hammick, M., \& Koppel, I. (2008). Interprofessional education: Effects on professional practice and health care outcomes. Cochrane Database of Systematic Reviews, 2008(1), 1-24. doi 10.1002/14651858.CD002213.pub2.

Rogers, A., Brooks, H., Vassilev, I., Kennedy, A., Blickem, C., \& Reeves, D. (2014). Why less may be more: A mixed methods study of the work and relatedness of 'weak ties' in supporting long-term condition self-management. Implementation Science, 9, 19. http://dx.doi.org/10.1186/1748-5908-9-19

Sadler, E., Wolfe, C. D. A., \& McKevitt, C. (2014). Lay and health care professional understandings of self-management: A systematic review and narrative synthesis. SAGE Open Medicine, 2. http://dx.doi.org/ 10.1177/2050312114544493

Satink, T., Cup, E. H., Ilott, I., Prins, J., de Swart, B. J., \& van der Sanden, M. W. N. (2013). Patients' views on the impact of stroke on their roles and self: A thematic synthesis of qualitative studies. Archives of Physical Medicine and Rehabilitaiton, 94(6), 1171-1183.

Star, S. L., \& Greisemer, J. R. (1989). Institutional ecology, 'translations' and boundary objects: Amateurs and professionals in Berkley's Museum of Vertebral Zoology, 1907-39. Social Studies of Science, 19, 387-420.

The Stroke Association (2016). The State of the Nation: Stroke Statistics. London, UK. https://www.stroke. org.uk/sites/default/files/stroke_statistics_2015.pdf : accessed 28th February 2016

Taylor, E., McKevitt C., \& Jones F. (2014). Factors shaping the delivery of acute inpatient stroke therapy: A narrative synthesis. Journal of Rehabilitation Medicine, 47(2), 107-119.

Taylor, D., \& Bury, M. (2007). Chronic illness, expert patients and care transition. Sociology of Health and Illness, 29(2), 27-45.

van Hooft, S. M., Dwarswaard, J., Jedeloo, S., Bal, R., \& van Staa, A. (2015). Four perspectives on self-management support by nurses for people with chronic conditions: A Q-methodological study. International Journal of Nursing Studies, 52(1), 157166.

Wiles, R., Ashburn, A., Payne, S., \& Murphy, C. (2004). Discharge from physiotherapy following stroke: The management of disappointment. Social Science \& Medicine, 59(6), 1263-1273.

Young, H. M. L., Apps, L. D., Harrison, S. L., Johnson-Warringon, V. L., Hudson, N., \& Singh, S. J. (2015). Important, misunderstood, and challenging: A qualitative study of nurses' and allied health professionals' perceptions of implementing selfmanagement for patients with COPD. International Journal of COPD, 10(1), 1043-1052. 